\title{
Erratum to: Contemplative Practice: Philosophy, Pedagogy, and Science
}

Correspondence:

chpmiller@ucdavis.edu

University of California, Davis, USA

\section{Erratum}

After publication of this editorial (Miller, 2016), it has been noted that unfortunately the following mention to the sixth article in the thematic series "Contemplative Studies in Dharma Traditions" failed to be included:

'Also looking at the contemporary period, Tillo Detige's piece explores ritual as a method of contemplative practice in the Jain tradition. Detige identifies what he calls "epistemic technologies," or those practices that seek to perform ritual texts to instill alternative forms of embodied, non-discursive knowledge. For scholars undertaking field research in the present, Detige's article suggests an innovative ethnographic methodology that one might apply in the context of any field study that considers contemporary dharma traditions.'

The paragraph should be read after the sentence 'Together, Pedersen and Biernacki present contemplative practices oriented toward transforming the worlds in which we live'.

The mention to 'five' articles in the thematic series should be replaced with 'six' instead.

Received: 6 December 2016 Accepted: 6 December 2016

Published online: 10 January 2017

\section{Reference}

Miller, C. 2016. Contemplative Practice: Philosophy, Pedagogy, and Science. Int J Dharma Studies 4: 12. doi:10.1186/s40613-016-0036-6 